\title{
Photovoltaic performance of injection solar cells and other applications of nanocrystalline oxide layers
}

\author{
K KALYANASUNDARAM and M GRÄTZEL* \\ Laboratory for Photonics and Interfaces (LPI), Swiss Federal Institute of \\ Technology at Lausanne (EPFL), CH-1015 Lausanne, Switzerland
}

\begin{abstract}
The direct conversion of sunlight to electricity via photoelectrochemical solar cells is an attractive option that has been pursued for nearly two decades in several laboratories. In this paper, we review the principles and performance features of very efficient solar cells that are being developed in our laboratories. These are based on the concept of dye-sensitization of wide bandgap semiconductors used in the form of mesoporous nanocrystalline membrane-type films. The key feature is charge injection from the excited state of an anchored dye to the conduction band of an oxide semiconductor such as $\mathrm{TiO}_{2}$. In the use of the semiconductor in the form of high surface area, highly porous film offers several unique advantages: monomeric distribution of a large quantity of the dye in a compact (few micron thick) film, efficient charge collection and drastic inhibition of charge recombination ("capture of charge carriers by oxidized dye'). Near quantitative efficiency for charge collection for monochromatic light excitation gives rise to sunlight conversion efficiency in the range of $8-10 \%$ This has led to fruitful collaboration with several industrial partners. Possible applications and commercialization of these solar cells and also other practical applications of nanosized films are briefly outlined.
\end{abstract}

Keywords. Solar energy; photoelectrochemical solar cells; sunlight energy; photosensitizers.

\section{Introduction}

Photochemical approaches to conversion of solar energy can be broadly classified into two main domains ${ }^{1-5}$. One uses the sunlight to drive net conversion of chemicals from one form to another. Modelling of primary photoprocesses of green plant and bacterial photosynthesis has been the goal of many studies in the eighties. Photolysis of water to high energy content fuel $\mathrm{H}_{2}$ and photofixation of $\mathrm{CO}_{2}$ to chemical products (" $\mathrm{C} 1$ chemistry") can be cited as typical examples. In the nineties, greater emphasis is being given for achieving industrially/ecologically useful chemical reactions. Photodegradation of toxic pollutants using particulate suspensions of semiconducting oxides largely dominates these types of studies.

The other photochemical approach is for conversion of sunlight energy to electrical energy. The latter has the attraction that the photosystem can be compact in design and the electric power can be used later for a wide variety of tasks. Photogalvanic cells based on photoredox reactions of solution-dispersed dyes and liquid-junction solar cells based on light-induced charge carrier separation at semiconductor-electrolyte interfaces are the two widely studied approaches. In the former type of cells, kinetically fast back electron-transfer reactions that occur following photoinduced electron transfers heavily limit the efficiency

\footnotetext{
*For correspondence
} 
of charge collection at macro electrodes. This has led to total abandoning of this approach in recent times. In contrast, liquid-junction solar cells based on single crystals of lowbandgap semiconductors (III-V materials such as InP or layer materials such as $\mathrm{MoS}_{2}$ or $\mathrm{WSe}_{2}$ ) have been shown to give respectable sunlight-to-electrical conversion efficiency, in the range of $15-20 \%$. Two major reasons that limit large scale, practical implementation of these solar cells are the high cost of single crystalline materials and the problem of photochemical stability ('photocorrosion') of the low bandgap semiconductors. Oxide semiconductors show exceptional chemical stability but their high bandgap energy limit the amount of useful light energy harvesting.

Significant advances in the fields of colloid and sol-gel chemistry in the last two decades 6-14 now allow fabrication of micro- and nano-sized structures using finely divided monodispersed colloidal particles. These, in turn, are used to develop systems of smaller dimensions. Nanocrystalline semiconductor films are constituted by a network of mesoscopic oxide or chalocogenide particles such as $\mathrm{TiO}_{2}, \mathrm{ZnO}, \mathrm{Nb}_{2} \mathrm{O}_{5}, \mathrm{WO}_{3}, \mathrm{Ta}_{2} \mathrm{O}_{5}, \mathrm{CdS}$ or $\mathrm{CdSe}$, which are interconnected to allow electronic conduction to take place. The pores between the particles are filled with a semiconducting or a conducting medium, such as a p-type semiconductor, a hole transmitter or an electrolyte, forming a junction of extremely large contact area. In this fashion, the negatively and positively charged contact of the electric cell become interdigitated on a length scale as small as a few nanometers. Nanostructured materials offer many new opportunities to study fundamental processes in a controlled manner and this in turn lead to fabrication of new devices, some of which are summarized in figure 1. The unique optical and electronic features of these are being exploited to develop opto-electronic devices such as photoelectrode in solar cells, photochromic displays/ switches, optical switches, chemical sensors, intercalation batteries, capacitor dielectrics/supercapacitors, heat-reflecting and UV-absorbing layers, coatings to improve chemical and mechanical stability of glass etc. In some recent articles ${ }^{15-16}$ we have outlined some of these novel applications.

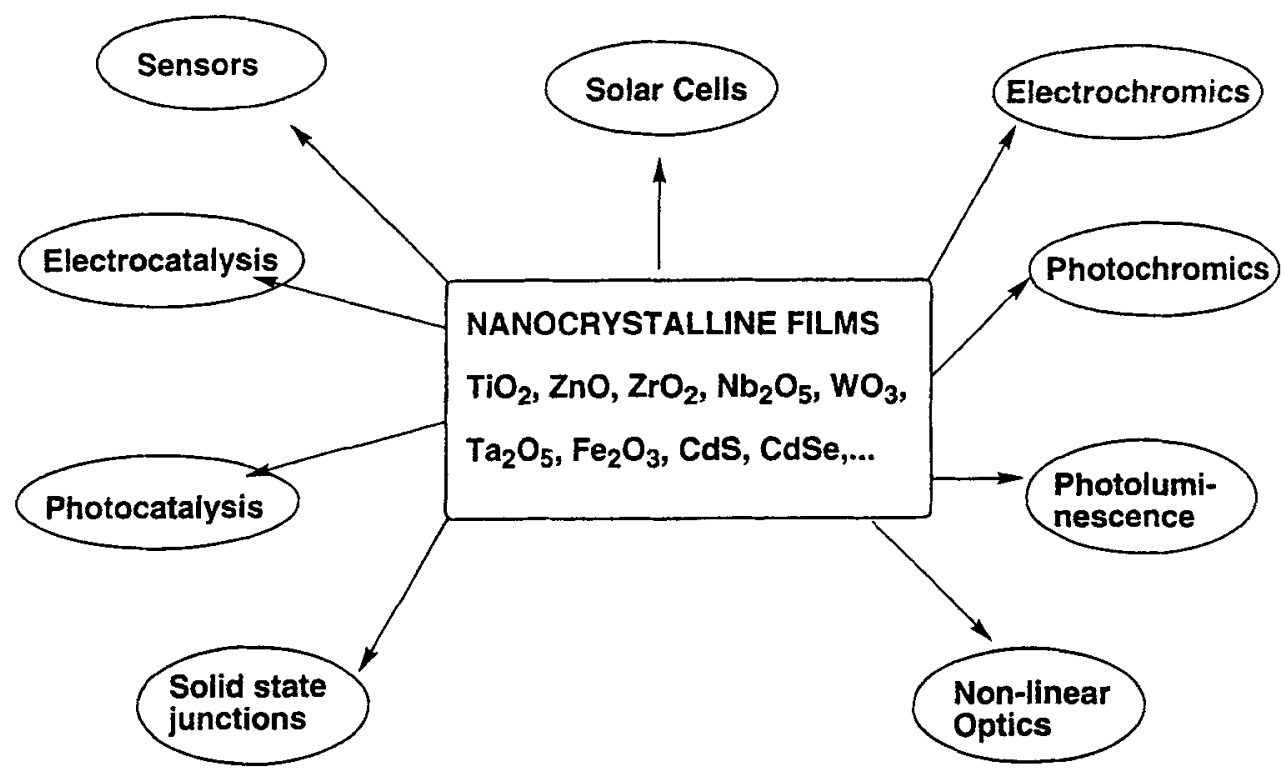

Figure 1. Applications of nanocrystalline mesoporous films. 
The approach to photochemical solar energy conversion that we have undertaken in Lausanne $e^{17-23}$ has been not to go for a hybrid system that will use some of the positive features of the various above cited approaches but use an architecture based on nanosized films that will limit significantly the role of undesirable side reactions. Nanocrystalline solar cells based on titanium dioxide reviewed in this paper is the outcome of this approach. Photoinduced electron transfer from the excited state of an anchored dye to the conduction band of the semiconductor in engineered membrane films allow efficient decoupling of the primary charge separation and charge collection steps. Results very similar to ours have also been obtained in several other laboratories ${ }^{24-29}$. Dye sensitization forms the basis for applications in the fields of photography, photochromic devices and photolithography ${ }^{30-31}$. Hence there has been a long standing interest in the study of this phenomenon, particularly on semiconductor electrodes ${ }^{32-34}$.

$\mathrm{TiO}_{2}$ is by far the most commonly used white pigment, with current world-wide annual consumption of $\approx 3$ million tons. Global $\mathrm{TiO}_{2}$ industry is worth more than 5.5 billion US\$. In the present era of ecological and environmental consciousness, it is virtually an inert, non-toxic compound. Its extensive usage in paint industry comes from its high refractive index and ease of preparation of particles of very small size (leading to large surface area). As a cheap, readily available material, $\mathrm{TiO}_{2}$ serves as an attractive candidate for many industrial applications (paints, paper, coatings plastics, fibres, cosmetics,..). It is a wide bandgap semiconductor with $E_{b g} \approx 3 \cdot 2 \mathrm{eV}$. Interests on the use of $\mathrm{TiO}_{2}$ for light energy conversion can be traced to early seventies with the reports of Fujishima and $\mathrm{Honda}^{35}$, on the possible use of $\mathrm{TiO}_{2}$ as a photoelectrode to decompose water to oxygen.

\section{Schematics of the solar cell}

Figure 2 presents a cartoon of the make-up of the dye-sensitized solar cells based on nanocrystalline films of $\mathrm{TiO}_{2}$. The solar cell consists of two conducting glass electrodes

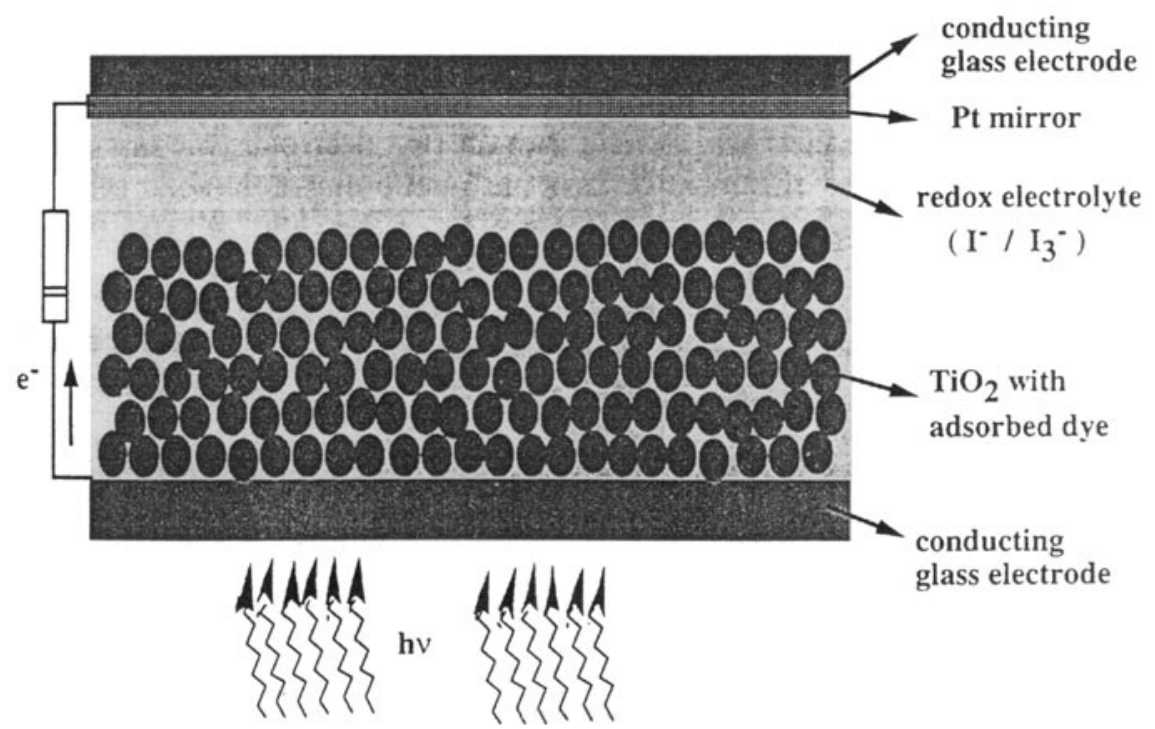

Figure 2. A schematic representation of the dye-sensitized photoelectrochemical cell showing various components. 


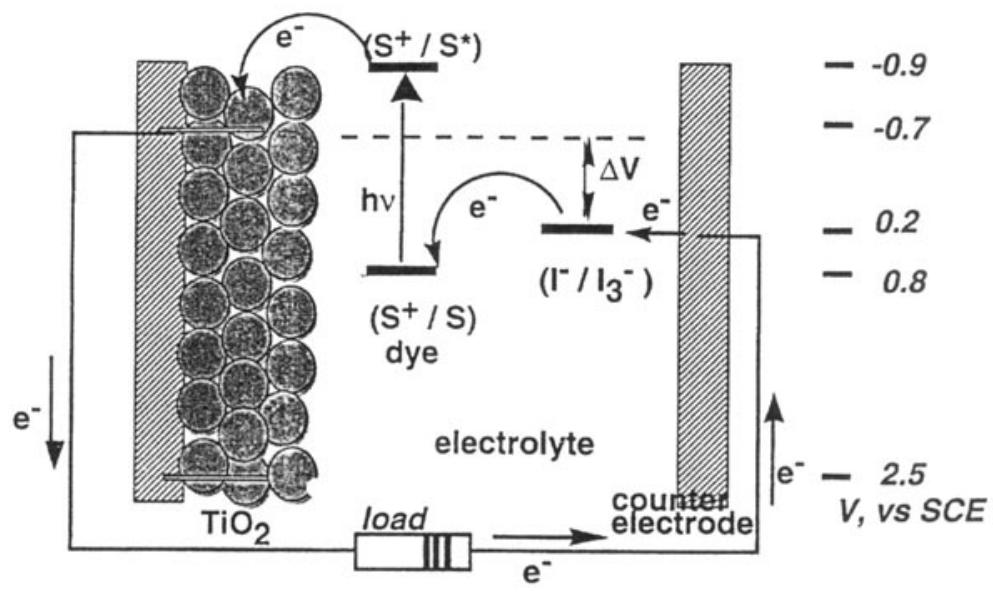

Figure 3. Principles of operation of dye-sensitized photovoltaic cell based on nanocrystalline $\mathrm{TiO}_{2}$ layers.

with a redox electrolyte separating the two. On one of these electrodes, a few micron-thick layer of $\mathrm{TiO}_{2}$ is deposited using a colloidal preparation of monodispersed particles of $\mathrm{TiO}_{2}$. The compact layer is porous with a high surface area, allowing monomolecular distribution of dye molecules. After appropriate heat treatment to reduce the resistivity of the film, the electrode with the oxide layer is immersed in the dye solution of interest (typically $2 \times 10^{-4} \mathrm{M}$ in alcohol) for several hours. The porous oxide layer acts like a sponge and there is very efficient uptake of the dye, leading to intense coloration of the film. Molar absorbances of 3 and above are readily obtained within the micron-thick layer with a number of Ru-polypyridyl complexes. The dye-coated electrode is then sandwiched with another conducting glass electrode and the intervening space is filled with an organic electrolyte (glutaronitrile) containing a redox electrolyte $\left(\mathrm{I}^{-} / \mathrm{I}_{3}^{-}\right)$. A small amount of $\mathrm{Pt}\left(5-10 \mu \mathrm{g} / \mathrm{cm}^{2}\right)$ is deposited to the counter-electrode to catalyze the cathodic reduction of triiodide to iodide. After making provisions for electrical contact with the two electrodes, the assembly is sealed.

Evan though some of the finer details of the functioning of the solar cell are yet to be understood, the general principles of operation of the solar cell can be outlined as shown in figure 3. Optical excitation of the dye with visible light leads to excitation of the dye to an electronically excited state that undergoes electron-transfer quenching, injecting electrons into the conduction bands of $\mathrm{TiO}_{2}$;

$$
S^{*} \longrightarrow S^{+}+\mathrm{e}_{c b}^{-} \text {. }
$$

The oxidized dye is subsequently reduced back to the ground state $(S)$ by the electron donor $\left(I^{-}\right)$present in the electrolyte filling the pores,

$$
2 S^{+}+3 I^{-} \longrightarrow 2 S+I_{3}^{-} \text {. }
$$

The electrons in the conduction band, after visiting several $\mathrm{TiO}_{2}$ particles arrive at the back collector electrode by a process known as 'percolation'. The electrons subsequently pass through the external circuit to arrive at the counter electrode where they effect the reverse reaction of the redox mediator, viz., regeneration of the iodide

$$
I_{3}^{-}+2 e-\longrightarrow 3 I^{-} \text {(at the counter electrode). }
$$


The nett of visible light irradiation is regeneration of the dye, the redox mediator and the driving of electron through the external circuit, that is, direct conversion of sunlight to electricity. If all the reactions take place as indicated and nothing else, the solar cell will deliver photocurrents indefinitely. The maximum photovoltage obtainable will be the difference between the Fermi levels of the conduction band of $\mathrm{TiO}_{2}$ under illumination and the redox potential of the mediating redox couple. The photocurrent obtainable is a complex entity depending on the spectral, redox properties of the dye and on the structure and morphological properties of the oxide layer.

\section{Performance of the solar cell}

Figure 4 presents the photocurrent action spectrum for one of the configurations currently used as a standard. The cell uses the Ru-complex $\left[\mathrm{Ru}(\mathrm{dcbpy})_{2}(\mathrm{NCS})_{2}\right]$ as the sensitizer and $\left(I^{-} / I_{3}^{-}\right)$dissolved in glutaronitrile as the redox electrolyte. Plotted on the left is incident photon-to-current conversion efficiency (IPCE) as a function of the excitation wavelength (for monochromatic excitation). The IPCE value is the ratio of the observed photocurrent divided by the incident photon flux, uncorrected for reflective losses for optical excitation through the conducting glass electrode,

$$
I P C E=\frac{\text { no. of electrons flowing through the external circuit }}{\text { no. of photons incident }} .
$$

The IPCE value can be considered as the effective quantum yield of the device and it is the product of three key factors: (a) light harvesting efficiency LHE $(\lambda)$ (depend on the spectral and photophysical properties of the dye); (b) the charge injection yield $\phi_{i n j}$ (depend on the excited state redox potential and the lifetime) and (c) the charge

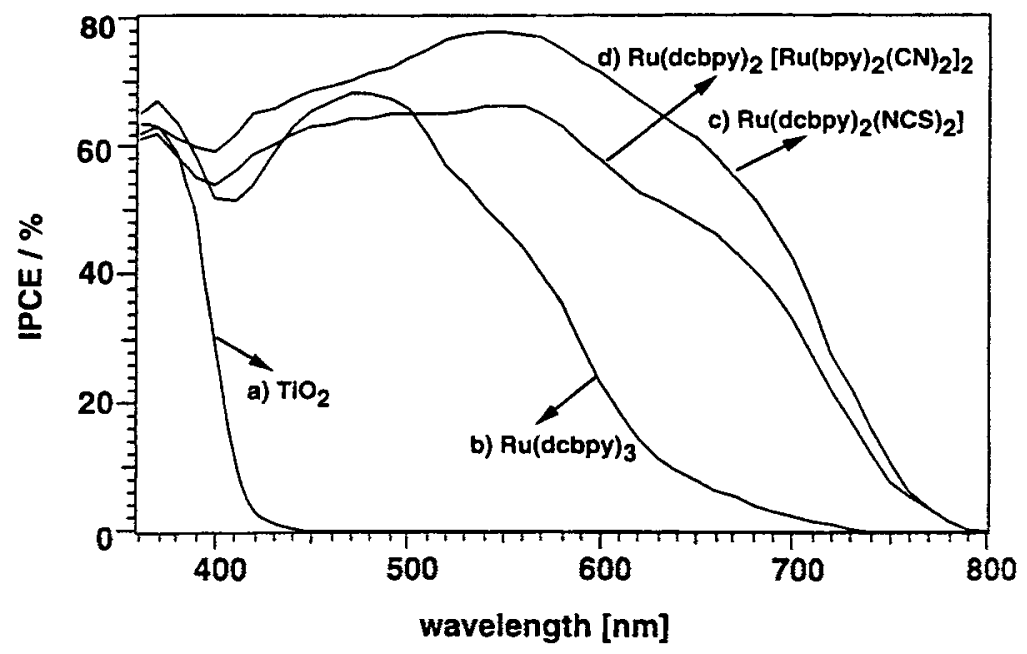

Figure 4. Representative photocurrent action spectra obtained on nanocrystalline $\mathrm{TiO}_{2}$-based solar cells. Shown are output curves for bare $\mathrm{TiO}_{2}$ surface and also for three Ru-complexes, $\left[\mathrm{Ru}(\mathrm{dcbpy})_{3}\right],\left[\mathrm{Ru}(\mathrm{dcbpy})_{2}(\mathrm{NCS})_{2}\right]$ and $\mathrm{Ru}(\mathrm{dcbpy})_{2}\left[\mathrm{Ru}(\mathrm{bpy})_{2}(\mathrm{CN})_{2}\right]_{2}$. The size of the working electrode was ca. $0.5 \mathrm{~cm} 2$, the counter electrode was a conducting glass electrode covered with a transparent film of $\mathrm{Pt},\left(I^{-} / I_{3}^{-}\right)$as the redox electrolyte and the cell operated in the short-circuit mode. 


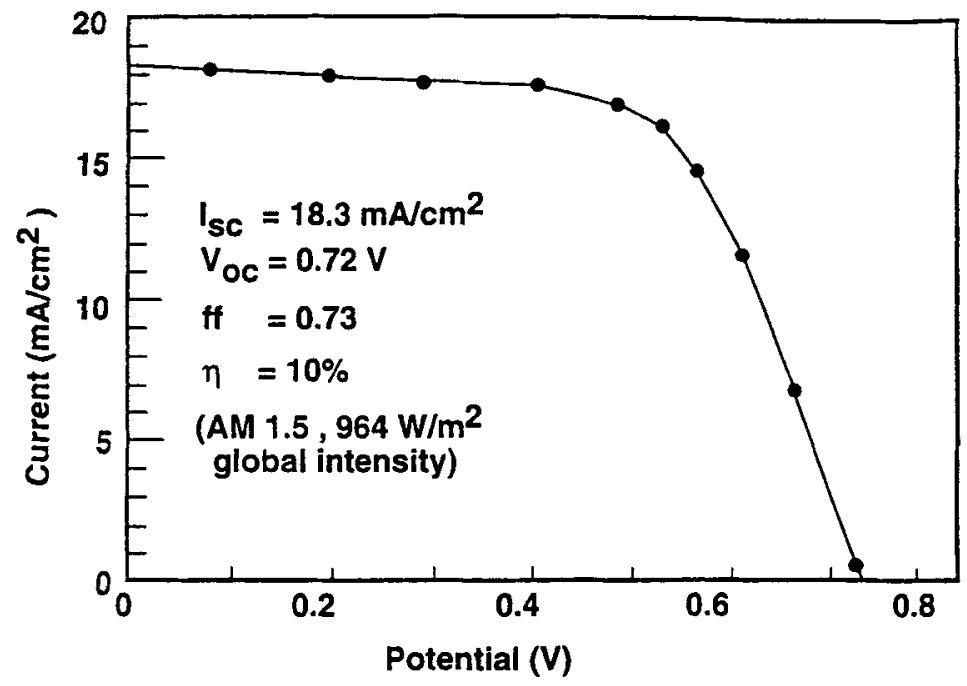

Figure 5. Photocurrent-voltage curve for a sealed nanocrystalline photovoltaic cell based on [Ru(dcbpy $\left.)_{2}(\mathrm{NCS})_{2}\right]$ as the sensitizer, $\left(I^{-} / I_{3}^{-}\right)$as the redox electrolyte in acetonitrile/ $\mathrm{N}$-methyloxazolidinone.

collection efficiency $\eta_{e l}$ (depend on the structure and morphology of the $\mathrm{TiO}_{2}$ layer). It can be noted that the IPCE values in excess of $85 \%$ obtained in the region correspond to the absorption maximum of the Ru-complexes $(400-550 \mathrm{~nm})$. Near unit values of IPCE suggest that, in the present case, the charge injection and charge collection steps operate at optimal efficiencies.

Figure 5 presents the power output characteristics of the $\mathrm{TiO}_{2}$-based solar cell. The overall efficiency $\left(\eta_{\text {global }}\right)$ of the photovoltaic cell can be obtained as a product of the integral photovoltaic density $\left(i_{p h}\right)$, the open-circuit photovoltage $\left(V_{o c}\right)$, the fill factor $(f f)$ and the intensity of the incident light $\left(I_{s}\right)$

$$
\eta_{\text {global }}=\left\{i_{p h} \times V_{o c} \times f f\right\} / I_{s}
$$

For irradiation with simulated sunlight corresponding to approximately one sun (AM $1.5,900 \mathrm{~mW} / \mathrm{cm}^{2}$ ), the overall white light to electrical conversion efficiency is $\approx 10 \%$. In typical lab experiments, solar cells with irradiation area of $1-2 \mathrm{~cm}^{2}$ are made and tested. The power output characteristics of the cell is strongly dependent on the structure and morphology of the porous, nanocrystalline film and surface treatments are often necessary for optimal performance. The fill factor, for example, improves drastically after treatment of the oxide layer with a solution of an electron donor such as tert-alkyl pyridine. After nearly five years of optimization, in routine preparations, solar cells can be made that deliver short-circuit photocurrent in the range of $15-18 \mathrm{~mA} / \mathrm{cm}^{2}$ and photovoltages of $\approx 600-700 \mathrm{mV}$.

Key components of the solar cells

There are many key components that influence significantly the performance of the solar cell and these are reviewed, one by one. As far as choice of sensitizers is concerned, our emphasis has been on polypyridyl complexes of $\mathrm{Ru}$. These complexes exhibit 


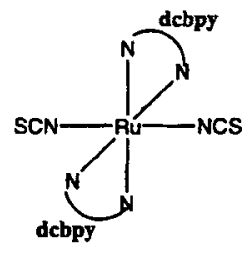

$\mathrm{Ru}(\mathrm{dcbpy})_{2}(\mathrm{NCS})_{2}$

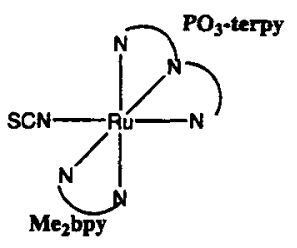

$\mathrm{Ru}\left(\mathrm{PO}_{3}\right.$-terpy)(Me $\mathbf{2}_{2}$ bpy)(NCS)

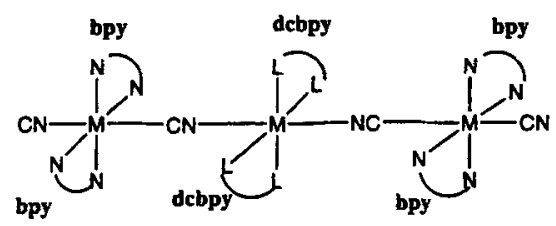

$\mathrm{Ru}(\mathrm{dcbpy})_{2}\left[\mathrm{Ru}(\mathrm{bpy})_{2}(\mathrm{CN})_{2}\right]_{2}$<smiles>O=P(O)(O)C1C=C(c2ccccn2)NC(c2ccccn2)C1</smiles>

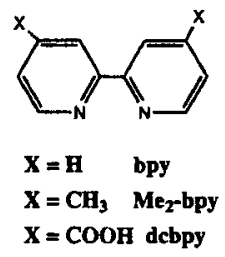

Figure 6. Select examples of efficient photosensitizers of the Ru-polypyridine complex family for use on nanocrystalline $\mathrm{TiO}_{2}$-based solar cells.

strong visible light absorption arising from charge transfer transitions from filled $d$ orbitals $\left(t_{2 g}\right)$ of the central metal ion (Ru) to the empty $\pi^{*}$ orbitals bipyridine ligand. The MLCT excited states are fairly long-lived in fluid solutions and undergo efficient electron-transfer reactions. In the last two decades a vast amount of literature has grown on the photophysics and photochemical properties of these complexes ${ }^{36-41}$. Quantitative analysis of the spectral, electrochemical and photophysical properties of several hundred complexes have led to clear understanding of the CT transitions, that it is now feasible to tailor-make complexes with desired properties. Figure 6 shows some representative examples of Ru-complexes that have been successfully employed as efficient photosensitizers.

\section{Nanoporous $\mathrm{TiO}_{2}$ layer}

The performance of the solar cell is intimately based on the material content, chemical composition, structure and morphology of the nanoporous oxide layer. Fortunately, colloid chemistry has advanced tremendously in the last two decades that, it is now possible to control the processing parameters such as precursor chemistry, hydrothermal growth temperature, binder addition and sintering conditions and optimize the key parameters of the film viz., porosity, pore size distribution, light scattering, electron percolation. 
On the material content, two crystalline forms of $\mathrm{TiO}_{2}$ are important, the anatase and rutile (the third form Brookite is difficult to obtain). Anatase is the low-temperature stable form (appears in the form of pyramid-like crystals) and rutile (needle-like) is the dominant form in high temperature form, including single crystals. Rutile has nonnegligible absorption in the near-UV region $(350-400 \mathrm{~nm}), \approx 4 \%$ of the solar radiation incident. Excitation within the bandgap leads to generation of holes, a strong oxidant causing long term instability of the solar cell.

For efficient dye distribution, the surface area of the membrane film must be large. It is known that smaller the particle size, larger will be the surface area of the film. Earlier studies on single crystal semiconductor electrodes have shown that only a few monolayers of the dye can efficiently participate in the excited state charge injection process. The light harvesting from a planer electrode is poor due to the small absorption cross section of monolayer of the dye. In highly porous nanotextured films, the available surface area for dye adsorption can be enormous (with surface roughness factor over 500,) leading to near extinction of incident light within a few $\mu$-thick film.

Porosity is another factor that needs to be optimized. For the fast regeneration of the oxidized dye and charge transport, the redox electrolyte must be able to penetrate the pores efficiently and be present in places where the dye penetrates. Larger the particle size, the larger will be the porosity of the layer. Larger particles also scatter the incident radiation more effectively and this has been found to be a positive factor in enhancing the red-light response of the sensitizer. So the preparation procedure must be optimized so as to provide both an optimal particle size as well as porosity features: Sintering of the particles that form the film is another important step related to electron percolation within the film and reducing of dark currents. Sintering produces low resistance ohmic contacts between the particles. Thus the electrons injected anywhere within the network of particles can hop through several particles and reach the back contact without being lost (trapped) within the oxide layer.

The injected electron has to be transported across a large number of colloidal particles and grain boundaries. There will be an increased probability of recombination with increased film thickness. Thus there exists an optimal thickness to obtain maximum photocurrent. Another loss mechanism due to increasing film thickness is a resistance loss leading to a decrease in photovoltage and fill factor.

\section{Preparation of nanocrystalline $\mathrm{TiO}_{2}$ layer electrodes}

Preparation of nanocrystalline semiconductor films consists of two steps, preparation of colloidal solution containing monodispersed nanosized particles of the semiconductor and preparation of few micron-thick film with good electrical conduction properties using this colloidal solution. Figure 7 shows schematically, various steps involved in the preparation of nanocrystalline $\mathrm{TiO}_{2}$ layers for use in solar cells. Several publications from our group providing a detailed description of these steps and their influence on the performance of the solar cell are available ${ }^{42-52}$. Hence, we will only briefly review the key results.

Precipitation process involve controlled hydrolysis of a Ti(IV) salt, usually an alkoxide such as Ti-isopropoxide or a chloride followed by peptization. In order to obtain monodispersed particles of desired size, the hydrolysis and condensation kinetics must be controlled. Ti-alkoxides with bulky groups such as butoxy hydrolyze slowly, allowing slow condensation rates. It has been found that, Ti-propoxide, 


\title{
Preparation of nanocrystalline $\mathrm{TiO}_{2}$ films
}

\author{
Precipitation \\ (hydrolysis of Ti-alkoxides using 0.1M $\mathrm{HNO}_{3}$ )<smiles>[CH]1CC1</smiles> \\ Peptization $\left(8 \mathrm{~h}, 80^{\circ} \mathrm{C}\right)$ following by filtering \\ 1 \\ Hydrothermal growth /autoclaving $\left(12 \mathrm{~h}, 200-250^{\circ} \mathrm{C}\right)$ \\ 1 \\ Sonication (ultrasonic bath, $400 \mathrm{~W}, 15 \times 2 \mathrm{~s}$ )

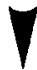 \\ Concentration $\left(45^{\circ} \mathrm{C}, 30 \mathrm{mbar}\right)$ \\ $\gamma$ \\ binder addition (carbowax/PEG, MW 20000) \\ (STOCK SOLUTION OF THE COLLOID) \\ $\vartheta$ \\ Layer deposition on conducting glass electrode \\ (F-doped $\mathrm{SnO}_{2}$, doctor blade technique)<smiles>C1C2CC12</smiles> \\ Sintering / binder burnout $\left(450^{\circ} \mathrm{C}, 30 \mathrm{~min}\right)$
}

Figure 7. Various steps involved in the preparation of nanocrystalline $\mathrm{TiO}_{2}$ layers on conducting glass electrodes for use in solar cells.

suitably modified with acetic acid or acetyl acetonate, give colloids of higher surface area $(\geqslant 200 \mathrm{~m} 2 / \mathrm{g})$ with small particle diameter $(5-7 \mathrm{~nm})$. Peptization step involves heating of the precipitate for $\approx 8 \mathrm{~h}$ at $80^{\circ} \mathrm{C}$. The process leads to segregation of the agglomerates to primary particles. In view of electrostatic factors that control colloid stability, peptization occurs more effectively at $p \mathrm{Hs}$ farther away from the isoelectric point. Particle growth has also been observed to some extent. The precipitate is then filtered through a glass frit to remove larger agglomerates and water added to the filtrate to reach a sol concentration of $\approx 5 \%$ by weight.

Autoclaving of these sols (heating at $200-250^{\circ} \mathrm{C}$ for $12 \mathrm{~h}$ ) allow controlled growth of the primary particles and also to some extent the crystallinity. During this hydrothermal growth, smaller particies dissolve and fuse to large particles by a process known as 'Ostwald ripening'. Higher the autoclaving $p \mathrm{H}$, more effective is the Ostwald ripening. Aggregation is less efficient at low autoclaving temperatures. The pore size distribution of the film depend on the aggregate size and distribution. Average aggregate size of 100 , 270 and $440 \mathrm{~nm}$, for example, gives rise to average pore sizes of 10,15 and $20 \mathrm{~nm}$ respectively. Higher the autoclaving temperature, more rutile formation occurs, 
particularly at temperatures above $240^{\circ} \mathrm{C}$. Electrodes prepared using colloids autoclaved at or below $230^{\circ} \mathrm{C}$ are transparent while those made from colloids autoclaved at higher temperatures are translucent or opaque. Each of these have their own advantages. Solar cells are usually made on a $240-250^{\circ} \mathrm{C}$ autoclaved colloidal solution with a film thickness of $10 \mu \mathrm{m}$, whereas for electrochromic display applications, it is desirable to use a solution autoclaved at $200^{\circ} \mathrm{C}$ giving a transparent $3-4 \mu \mathrm{m}$ thick film. Sedimentation takes place to some extent during the hydrothermal growth procedure and the precipitates are redispersed using a Ti-ultrasonic horn $(15 \times 2 \mathrm{~s}$ pulses at $400 \mathrm{~W}$ ). The sol is then concentrated at $45^{\circ} \mathrm{C}$ on a rotary evaporator to reach a final concentration of $\approx 11 \%$. An increase in the porosity of the film can be obtained by adding a binder such as polyethylene glycol (MWt 20000) to the above sol.

The sol is now ready for deposition on the conducting glass substrate. In our laboratory, we use $\mathrm{F}$-doped $\mathrm{SnO}_{2}$ glass from NSG (Nippon Sheet glass, $R=8-10 \Omega /$ square) and the sol is deposited by the doctor blade technique to get a film thickness of $100 \mu$. In routine work, a piece of scotch tape at the edges of the support determined the thickness of the film. Commercial powders of $\mathrm{TiO}_{2}$ such as P-25 (Degussa), F387 (Degussa) have also been used in place of the hydrolyzates of titanium alkoxides. [P-25 is formed by the hydrolysis of $\mathrm{TiCl}_{4}$ in a hot flame. The relatively short residence time necessary for the conversion of $\mathrm{TiCl}_{4}$ to $\mathrm{TiO}_{2}$ gives a product which has high surface area $\left(\approx 50 \mathrm{~m}^{2} / \mathrm{g}\right)$ and is a mixture of approximately $4: 1$ anatase to rutile). In this case, the $\mathrm{TiO}_{2}$ powder was dispersed by grinding with water and particle stabilizers (such as acetylacetone or $\mathrm{HNO}_{3}$ ) followed by addition of a non-ionic surfactant such as triton X-100 to improve the wettability and finally spread on the support as with the sols.

The films are then dried in air and then fired at $450^{\circ} \mathrm{C}$ in air for $30 \mathrm{~min}$. The film thickness was typically $5-10 \mu$ and the film mass about $1-2 \mathrm{mg} / \mathrm{cm}^{2}$. Analysis of the porous films (carbon content) indicate that the binder is totally burnt out. Increase of the firing temperature leads to sintering and pore coarsening. Small pores ( $\leqslant 10 \mathrm{~nm}$ ) decrease substabtially and average pore size increases from $15 \mathrm{~nm}\left(400^{\circ} \mathrm{C}\right)$ to $20 \mathrm{~nm}$ at $550^{\circ} \mathrm{C}$. Sintering at $350-450^{\circ} \mathrm{C}$ produces electronic contact not only between the particles and the support but also between all the particles constituting the film. Thus a sponge-like structure is obtained and the colloidal $\mathrm{TiO}_{2}$ film is porous (typically a porosity of $50 \%$ is achieved) from the outer layers to the ITO contact. The pores between the colloidal particles are interconnected and can be filled with an electrolyte. A roughness factor, defined as the ratio between the real and the projected surface of these films, of about 1000 has been estimated for a $10 \mu \mathrm{m}$ thick $\mathrm{TiO}_{2}$ film.

Studies have shown that deposition of a secondary oxide layer to the nanotextured film improves significantly the cell performance. In one procedure the film in impregnated with $\mathrm{TiCl}_{4}$ by immersing the film in a solution in ice water (conc. $0.2 \mathrm{M}$ ) followed by firing at $450^{\circ} \mathrm{C}$ for $30 \mathrm{~min}$. Electrochemical deposition of $\mathrm{TiO}_{2}$ on the nanotextured film can also be carried out by anodic oxidative hydrolysis of $\mathrm{TiCl}_{3}$. Typically $0.1-0.35 \mathrm{mg} / \mathrm{cm}^{2}$ (projected area) of $\mathrm{TiO}_{2}$ was deposited galvanostatically on top of $\mathrm{TiO}_{2}$ layer on ITO or Ti sheet. One possible effect of the secondary layer is to increase the electron percolation in the film.

\section{Key steps in the functioning of the solar cell}

The overall performance of the solar cell is the outcome of several key steps, (a) light absorption by the dye; (b) charge injection from the excited state of the dye to the 
conduction band of the semiconductor; (c) regeneration of the oxidized dye; (d) electron percolation within the oxide film; (e) dark currents; (f) counter-electrode performance and $(\mathrm{g})$ factors related to long term stability (UV-sensitivity of the oxide film, other side reactions of the dye in $S, S^{*}$ and $S+$ states) and material cost. In the following paragraphs, we will take up each of these key steps and discuss our understanding on them. Steps (e)-(f) depend on the properties of the oxide layer while steps (a) and (b) are related to the choice of the dye used as the sensitizer. The molecular engineering process of the dye involve three aspects: tuning of the spectral and redox properties of the dye and the introduction of suitable anchoring groups.

\section{Dye uptake and the red response}

The morphology of the oxide layer also affects the dye uptake and also the spectral response in the low energy region. In high surface area films composed of very small $\mathrm{TiO}_{2}$ particles, the pore size can limit the dye uptake, particularly for large size molecules. Feeble coloration is obtained due to low dye uptake that occurs with supramolecular molecules. So tuning of the pore size is necessary in these cases. The absorption of light by a monolayer of the dye adsorbed on to a flat semiconductor surface is weak due to the fact that the area occupied by one molecule is much larger than its optical cross section for light capture. High photovoltaic efficiency cannot be obtained in such a configuration. When the light penetrates the "spongy" semiconductor in the porous films, it crosses several hundreds of adsorbed dye monolayers. Thus the mesoscopic films fulfill a function similar to the thylakoid membranes of green leaves.

Secondly the photoresponse in the low energy region depend on the scattering properties of the film. As shown in figure 5, the IPCE values obtained in the red region is much higher than what is indicated by the absorption spectrum of the dye. At $700 \mathrm{~nm}$ for example, the absorption of the bisthiocyanato complex is hardly $5 \%$ of the maximum value corresponding to $530 \mathrm{~nm}$. Yet the IPCE value at 700 is nearly half. (Normally the photocurrent action spectrum reproduces the solution absorption spectrum, except for small changes caused by the derivatization of the dye on the electrode). In the wavelength region where the dye absorption is maximal, the high absorbance values $(>1.4)$ leads to total extinction of the light within the film, while in the low energy side, a significant part of the incident radiation penetrates the layer. Multiple reflections of the light in highly scattering films results in increased light absorption and hence increased photoresponse than what the solution absorption spectrum indicates. This dependence of the red light response indeed has been verified by incorporation of added scattering centers during the preparation of the nanocrystalline $\mathrm{TiO}_{2}$ film. In fact, in current efforts of dye design, particular attention is being paid to small but definitive absorption tail extending further into the red/near-IR region.

\section{Change injection from the excited state of the dye}

Efficient charge injection from the electronically excited state of the dye into the conduction band of $\mathrm{TiO}_{2}$ depend on the redox properties of the dye in the excited state $E\left(S^{+} / S^{*}\right)$. In cases where the reorganization energy for the formation of oxidized dye is small (as is often the case with Ru-polypyridine complexes), the reduction potential, $E\left(S^{+} / S^{*}\right)$ is given by,

$$
E\left(S^{+} / S^{*}\right)=E\left(S^{+} / S\right)+E\left(S^{*}\right)
$$


Electron transfer reactions involving semiconductor valence and/or conduction bands can be described by the same Marcus-type formulisms used for electron-transfer reactions of solution redox species, particularly for the rate dependence on the driving force associated with respective electron transfer steps ${ }^{53}$. Studies with numerous dyes have shown that, the excited state should have a driving force for the charge injection step (reaction 6) to be at least $250 \mathrm{mV}$ or larger. For dyes that are adsorbed or covalently bound to the oxide surface, the electron transfer is non-diffusional. It suffices for the excited state lifetime to be in the order of tens of nanoseconds.

In addition to ensuring homogeneous distribution of the dyes in the pores, one also needs to ensure that there is intimate contact (physical and electronic) between the dye and the semiconductor. There are several reasons for this. The deactivation of electronically excited state of dyes is generally rapid. Typical rate constant for the process $\left(k_{e f f}\right)$ is in the range of $10^{8}-10^{9} \mathrm{~s}^{-1}$. To achieve good quantum yield, the rate constant for the charge injection should be at least two orders of magnitude higher than $k_{\text {eff. }}$. This means that the charge injection rate has to exceed $10^{12} \mathrm{~s}^{-1}$. Fortunately this can be achieved via introduction of suitable anchoring groups on the ligand such as carboxyl or phosphonato on the polypyridine ligand. $4,4^{\prime}$-dicarboxy-2,2'-bipyridine (dcbpy) and 6-phosphonato-terpyridine are typical examples where the substituents play a primordial role in ensuring efficient adsorption of the dye on the surface of the amphoteric oxide $\mathrm{TiO}_{2}$ while preserving or promoting electronic coupling between the donor levels of the excited dye (an m.o which is largely $\pi^{*}$ of the ligand in character) and the acceptor levels of the semiconductor ( $3 \mathrm{~d}$ wave function/conduction band of $\mathrm{TiO}_{2}$ ). Figure 8 shows the photocurrent action spectrum for excited state charge injection

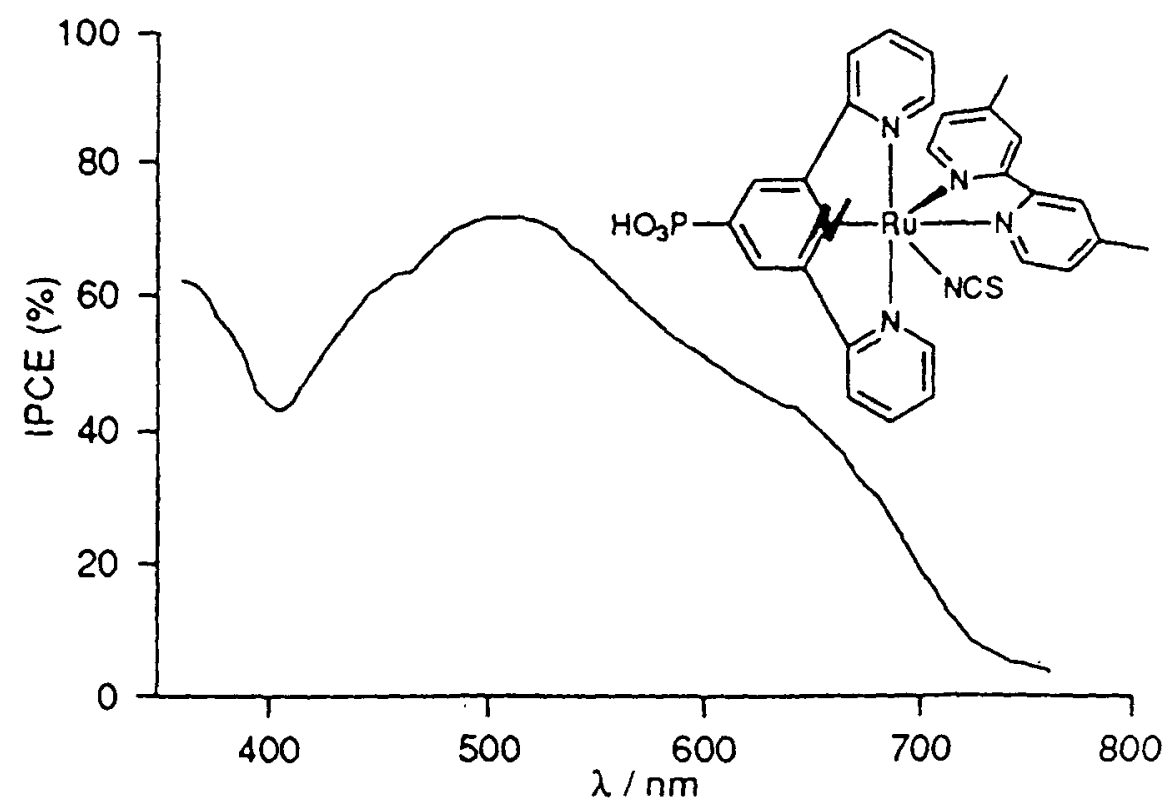

Figure 8. Photocurrent action spectrum for the sensitization of nanocrystalline $\mathrm{TiO}_{2}$ film by the $\mathrm{Ru}$-complex $\left[\mathrm{Ru}\left(\mathrm{PO}_{3}\right.\right.$-terpy $\left.)\left(\mathrm{Me}_{2}-\mathrm{bpy}\right)(\mathrm{NCS})\right]$. The conditions are as stated for figure 4 . 
from one such dye ${ }^{17,54}$ based on the $4^{\prime}$-phosphonato-2,2':6,2"-terpyridine ligand, [Ru(HP-terpy)( $\mathrm{Me}_{2}$ bpy)(NCS)].

Based on a comparison of $F T-I R$ and Resonance Raman spectral data of ester and carboxylate anion derivatives of the photosensitizer with that observed for dyes adsorbed on to $\mathrm{TiO}_{2}$ surface, presence of the ester form of the photosensitizer on the oxide surface has been inferred ${ }^{25,26}$. There are a number of literature precedents that suggests that carboxylic acid and hydroxylic groups effectively interact with the oxide surface ${ }^{55}$

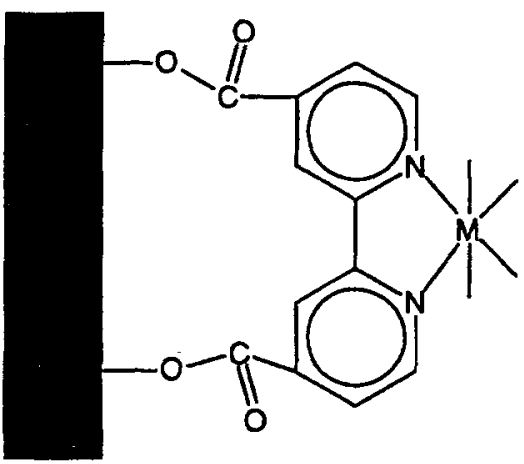

Dicarboxy-bipyridine

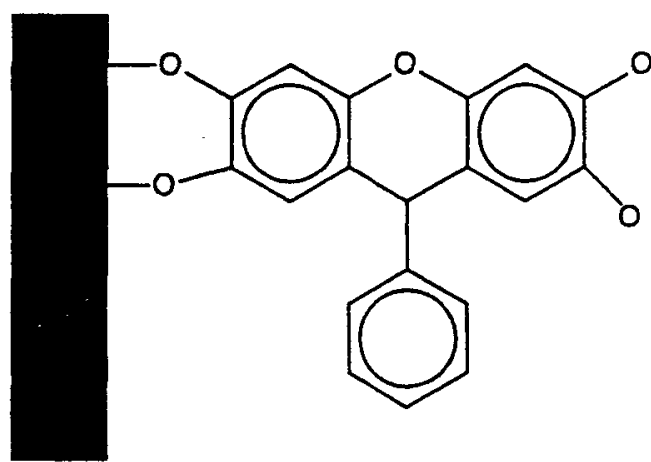

Phenyl fluorone

The adsorption of aryl and aliphatic carboxylic acids on $\mathrm{TiO}_{2}$, for example, has been shown to follow Langmuir isotherm ${ }^{56}$. Complexation of these acids on to $\mathrm{TiO}_{2}$ surface accelerates dramatically the rates of interfacial electron transfer to acceptors present in the solution. In favourable cases, derivatization of the ligands to the oxide surface leads to distinct spectral changes and/or build of new absorption bands corresponding to charge transfer interactions. Typical examples of this category are 8-hydroxyquinoline, $\mathrm{Fe}(\mathrm{CN})_{6}^{4-}$, phenyl fluorene and $\mathrm{Ru}(\mathrm{bpy})_{2}(\mathrm{CN})_{2}{ }^{57-59}$.

\section{Tuning of spectral properties}

Obviously one would like to use a dye that has near black body absorption-a dye that absorbs all of the sunlight incident on earth. The solar spectrum has maximal intensity in the IR region $(\approx 1200 \mathrm{~nm})$ and hence it is desirable to have dyes that have maximal absorbance in the visible/near-IR region. In polypyridine complexes of $\mathrm{Ru}(\mathrm{II})$ that we chose to work with, metal-to-ligand charge transfer (MLCT) transitions account for nearly all the visible light absorption by the dye. MLCT transition corresponds to promotion of an electron from an m.o that is largely Ru(II) based (filled $t_{2 g}$ level) to an m.o that is largely ligand based (empty $\pi^{*}$ orbital of the bipyridine ligand). Thus the smaller the energy gap, the more red-shifted is the related MLCT transition. The first oxidation and reduction potentials are good indicators of the electronic levels of the donor and acceptor MOs. The MLCT transition energy can be reduced either by tuning of the metal-based MO (' $2 \mathrm{G}$ tuning') or by tuning the polypyridine acceptor based $M O$ (' $\pi^{*}$ tuning'). We will discuss later special examples of dye design corresponding to these approaches. 


\section{Regeneration of the oxidized dye}

On thermodynamic grounds, the preferred process for the injected electron in the conduction band is to return to the oxidized sensitizer. Naturally this reaction is undesirable, since such back reactions generate only heat and not electrical current. For efficient processing of charge separated products, it is of interest to develop systems where there is orders of magnitude difference in the forward and back electron transfer rates. Fortunately, in the present case, these rates differ by more than a million. In contrast to the charge injection step which occurs in few picoseconds or less, the back reaction of the electrons of $\mathrm{TiO}_{2}$ with the oxidized Ru-complex is extremely slow, occurring typically in the microsecond time domain. The process involves a d-orbital localized on the Ru-metal whose electronic overlap with the $\mathrm{TiO}_{2}$ conduction band is small. This, together with the fact that the driving force for the back electron transfer is large enough to place it in the inverted Marcus region explains the relatively slow back electron transfer. Thus, in analogy to natural photosynthesis, light induced charge separation is achieved on kinetic grounds, the forward electron transfer being orders of magnitude faster than the back reaction. As a consequence, the presence of a local electrostatic field is not required to achieve good efficiencies for the process. This distinguishes nanocrystalline devises from conventional photovoltaic cells in that the successful operation of the latter is contingent upon the presence of a potential gradient within the $p-n$ junction.

For stable operation of the solar cell and maximal power output, the oxidized dye must be reduced back to the ground state as rapidly as possible by a suitable electron donor. Since the maximum photovoltage obtainable is related to the position of the mediator redox potential, it is preferable to choose a couple whose potential is as close to the $E\left(S^{+} / S\right)$ as possible. As with the charge injection step, the choice of the mediator should be such that, there is enough driving force $(\geqslant 250 \mathrm{mV})$ for the dye reduction step to have optimal rate. Thirdly, for stable performance of the solar for months, the redox couple must be fully reversible with no significant absorption of the visible light region and stability in the oxidized, reduced forms. The iodide/triiodide couple is currently being used as the redox mediator of choice. The electrolyte containing the mediator could be replaced by a p-type semiconductor, e.g. cuprous thiocyanate, $\mathrm{CuSCN}^{60}$ or cuprous oxide, $\mathrm{CuI}^{61}$ or a hole-transmitting solid, such as the amorphous organic compounds used in electroluminescence devices. These alternative options are being examined in our laboratory.

\section{Molecular engineering of photosensitizers}

From earlier discussions, it can be inferred that the molecular engineering of the dye needs to take into account the following: (a) tuning of spectral properties (MLCT absorption in the case of polypyridine complexes of $\mathrm{Ru}$ ) so as to ensure maximal visible light absorption; (b) tuning of redox properties in the ground and excited state, to ensure fast charge injection and regeneration of the oxidized dye and (c) introduction of anchoring groups to ensure uniform (monomolecular) distribution of the dyes on the oxide surface and to promote electronic coupling of the donor levels of the dye with the acceptor levels of the semiconductor and (iv) choice of counterions and degree of protonation (overall charge) to ensure sufficient solubility in organic, aqueous solvents and control of proton and water content in the pores during the loading of the dye. Some select examples of design strategies leading to identification of photosensitizers have been published earlier ${ }^{54,62-66}$. 
The $\mathrm{pK}_{\mathrm{a}}$ of the carboxylic groups in dcbpy is in the range of 2.5-3.0 in most of the Ru-complexes. Presence of water in the pores can lead to slow hydrolysis of the chelated ligand and release of the complex to the electrolyte and resulting loss of long term stability of the solar cell. Hence it was decided to search for ligands that are hydrolytically stable, particularly phosphonate groups as the anchoring group on bipyridine and/or terpyridine ligands. The photosensitizer $\left[\mathrm{Ru}\left(\mathrm{PO}_{3}\right.\right.$-terpy) $\left(\mathrm{Me}_{2}\right.$ bpy)(NCS)] (2) is an example of this type which appears to adhere to the $\mathrm{TiO}_{2}$ surface firmly and shows monochromatic and overall light to electrical conversion efficiency comparable to dcbpy-based complexes ${ }^{17.54}$.

\section{Supramolecular complexes as photosensitizers}

Even though the MLCT transitions of polypyridine complexes have a large bandwidth (over $80 \mathrm{~nm}$ ), for a single chromophore, the light harvesting capacity is rather limited. One approach for efficient harvesting of sunlight would be to link several graded series of chromophores in a "supramolecule" using appropriate spacer or bridging units. Higher energy chromophores could transfer the excitation energy to the lowest energy unit and charge injection can take place from this unit. The efficiency of intramolecular energy and electron-transfer processes in supramolecular assemblies will depend on the extent of electronic coupling between different chromophoric units as modulated by the bridge. Amphidentate ligands such as cyanide $\left(\mathrm{CN}^{-}\right)$and thiocyanate $\left(\mathrm{NCS}^{-}\right)$are attractive candidates in this context. These ligand-bridged complexes are very stable in multiple oxidation states of the metal centers ${ }^{64.66}$. Mixed valence form of these complexes show moderately intense inter-valence (IT) transitions that facilitate study of electronic coupling between the constituent units. The cyano-bridged complex $\mathrm{Ru}(\mathrm{dcpby})_{2}\left[\mathrm{Ru}(\mathrm{bpy})_{2}(\mathrm{CN})_{2}\right]_{2}(3)$ is a photosensitizer that belongs to this category. The central unit carrying dcbpy ligands and $\mathrm{N}$-bonded cyanides is the lowest energy chromophore. Time-resolved emission, absorption and emission studies have shown that efficient intramolecular energy transfer occurs from the peripheral units to the central unit. Even though it is a trinuclear complex, the MLCT transition energies are similar and hence the overall conversion efficiency of this complex is comparable to that of the mononuclear complexes (1) or (2). Recently we have made systematic studies of cyano-bridged trinuclear complexes of the type $\left[(\mathrm{X})(\mathrm{LL})_{2}\left(\mathrm{M}_{1}-\mathrm{CN}-\mathrm{M}_{2}(\mathrm{NN})_{2}\right.\right.$ $\mathrm{M}_{1}(\mathrm{LL})_{2}(\mathrm{X})$ ], where $\mathrm{M}_{1}, \mathrm{M}_{2}=\mathrm{Ru}, \mathrm{Os}, \mathrm{LL}, \mathrm{NN}=$ bpy, dcbpy and $\mathrm{X}=\mathrm{Cl}, \mathrm{H}_{2} \mathrm{O}, \mathrm{CN}$, etc $^{52}$. Depending on the nature of the metal, polypyridine and spectator ligands, the lowest energy chromophore can be placed on the central or peripheral units. Thus, by appropriate design, it is possible to construct supramolecules with a graded series of chromophores linked and follow the energy cascade upon excitation with white light.

\section{Infra-red photosensitizers and smart windows}

Studies have shown, that by appropriate control of the structure and morphology of the oxide layer and the amount, type of the dye used, it is possible to have semitransparent layers with fairly high white light-to-electrical conversion efficiency. This raises the possibility of using near-infra-red (even infra-red) light absorption complexes as photosensitizers. As with liquid-junction solar cells that use semiconductor as the light absorbers, the optimal cut-off wavelength for efficient harnessing of sunlight is $\approx 920 \mathrm{~nm}$. For photons of energy lower than this threshold, the useful photovoltage that can be obtained will be too small for any practical applications. 
With infra-red photosensitizers one can envisage the situation of large area glass panels for houses where a major portion of the visible light is transmitted and the infra-red component is used for power generation during the daytime (an area known as 'smart windows'). Towards such goals, we have started examining the performance of dyes with strong absorption in the red/near-IR region. As part of his doctoral thesis work in our laboratories, Andreas Kay examined ${ }^{43}$ a number of chlorins (reduced porphyrins) as photosensitizers and obtained IPCE values in the range of 30-60\% for the principal band absorbing in the $650-700 \mathrm{~nm}$. Earlier, Kamat et al have observed similar observations.

In her doctoral thesis work ${ }^{67}$, Ana Wiederkehr found low charge injection ( $\approx 15 \%$ at the $690 \mathrm{~nm}$ band) from phthlocyanine derivatives such as Tetrakis (carboxypheny)porphyrinato zinc ( $\mathrm{Zn}$ TPPC). The low charge injection efficiency arises due to the high anionic charge of the dye and to the strong tendency of these phthalocyanine dyes to aggregate via stacking interactions. Such aggregation processes can be inhibited by introduction of suitable axial ligands and/or bulky substituents. Enhancement of IPCE values (observed upon introduction of alkylamines (that axially bind to ZnTPPC) vindicate such hypothesis. In a very recent work, we have found a number of phthalocyanine derivatives serve as useful sensitizers for the injection solar cells of the present kind.

\section{Electron percolation with the film}

As mentioned earlier, electron percolation refers to the process by which the injected electrons hop through the colloidal oxide particles and arrive at the collector conducting glass electrode ${ }^{68}$. An ideal description of the film would be as a collection of large number of particles interconnected with large pores in between, that electrons injected onto any of the constituent particle can traverse through the network and reach the collector/back electrode. High IPCE values (in excess of $85 \%$ ) indicate that the electron percolation in the nanoporous films can be a very efficient process. From a fundamental point of view, this is one of the most intriguing processes amongst many that takes place in the solar cell. The picture elaborated below possibly applies to dye-sensitized case as well.

Figure 9 presents schematically the charge separation processes that occur in nanocrystalline oxide films following excitation of the semiconductor with light of energy equal or greater than the bandgap energy. There have been a number of studies devoted to the mechanism of charge separation in nanosized semiconductor films and their results have been reviewed elsewhere ${ }^{16,68}$. Here we cite only some key points. In these nanocrystalline porous films, the electrolyte penetrates the whole colloidal film up to the surface of the back contact and a semiconductor-electrolyte junction occurs thus at each nanocrystal, much like a normal colloidal system. During illumination, light absorption in any individual colloidal particle will generate an electron-hole pair. Assuming that the kinetics of charge transfer to the electrolyte is much faster for one of the charges (holes for $\mathrm{TiO}_{2}$ ) than the recombination processes, the other charge (electrons) can create a gradient in the electrochemical potential between the particle and the back contact. In this gradient, the electrons (for $\mathrm{TiO}_{2}$ ) can be transported through the interconnected colloidal particles to the back contact, where they are withdrawn as a current.

The charge separation in a nanocrystalline semiconductor therefore does not depend on a built-in electric field, i.e. a Schottky barrier, but is mainly determined by 


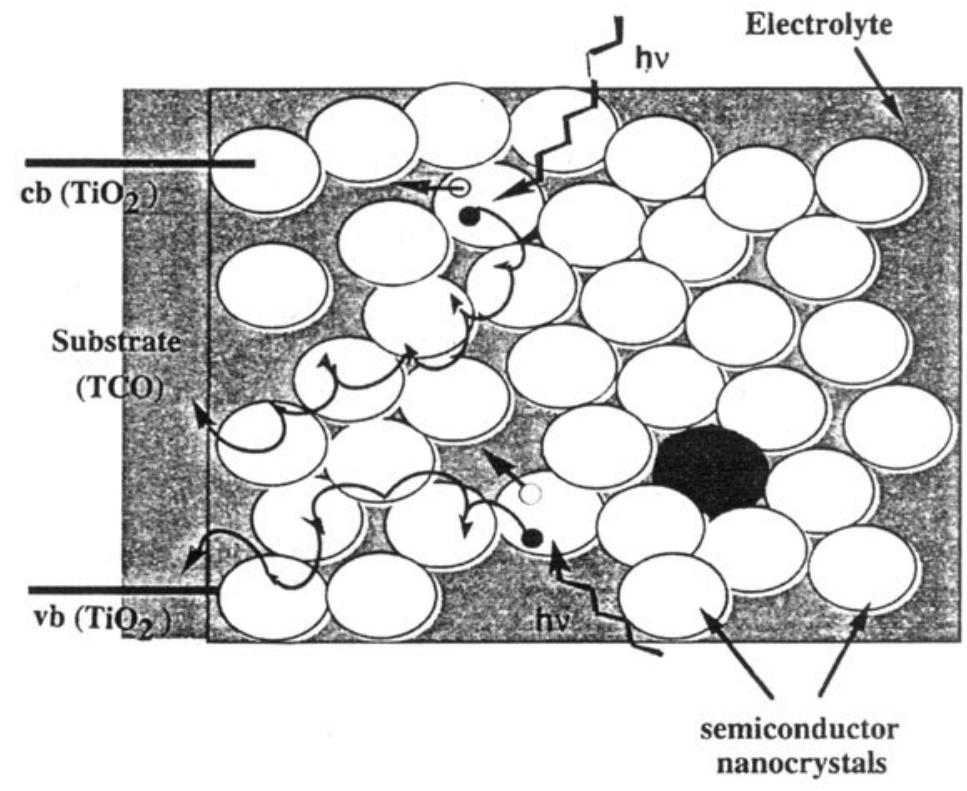

Figure 9. Charge separation and electron transport/ (percolation) processes in nanocrystalline films.

kinetics at the semiconductor-electrolyte interface. The creation of light induced electrochemical potential for the electrons in $\mathrm{TiO}_{2}$ also explains the building up of a photovoltage. There will be an increased probability of recombination with increased film thickness, as the electron has, on average, to be transported across an increasing number of colloidal particles and grain boundaries. This indeed has been observed experimentally. Thus there exists an optimal thickness to obtain maximum photocurrent. Another loss mechanism due to increasing film thickness is a resistance loss leading to a decrease in photovoltage and fill factor.

\section{Dark current}

The oxide layer is an inter-connected network of particles with high porous interior. The dyes can penetrate everywhere and adsorb over a large surface area. The redox mediator also must penetrate the same domain so as to be present in the immediate vicinity of the photosensitizer. If the redox mediator gets to the back contact, dark currents arise from the reduction of the redox mediator by the collector electrode with the oxide layer,

$$
2 e-+I_{3}^{-} \longrightarrow 3 I^{-} \text {. }
$$

In principle, this charge recombination can occur at the surface of not only $\mathrm{TiO}_{2}$ but also on $\mathrm{SnO}_{2}$ because of the porous nature of the $\mathrm{TiO}_{2}$ film. In reality, the reaction occurs at the $\mathrm{TiO}_{2}$ particle/redox electrolyte interface due to the relatively large surface area of the nanocrystalline film.

In order to reduce the dark current, an oxide underlayer is deposited. Alternatively, exposure of the dye-coated electrode to a solution of a pyridine derivative (donor) such 
as 4-t-butylpyridine was found to improve dramatically the fill factor (ff) and the open-circuit voltage $\left(V_{o c}\right)$ of the device without affecting the short-circuit photocurrent $\left(i_{s c}\right)$ in a significant fashion. For example, the untreated electrode gave isc $=17.8 \mathrm{~mA} / \mathrm{cm}^{2}$, Voc $=0-38 \mathrm{~V}$ and $\mathrm{ff}=0.48$, corresponding to an overall conversion efficiency $(\eta)$ of $3.7 \%$. After the electrode is dipped in 4-t-butylpyridine, $V_{o c}$ increases to 0.66 , ff to 0.63 and $\eta$ to $8.5 \%$. The increase in the open circuit voltage and the fill factor is due to the suppression of the dark current at the semiconductorelectrolyte junction. The effect of the substituted pyridine can be rationalized in terms of its adsorption at the $\mathrm{TiO}_{2}$ surface, blocking the surface states that are active intermediates in the heterogeneous charge transfer.

\section{Counter electrode performance}

In our studies, we employ a F-doped $\mathrm{SnO}_{2}$ as the conducting glass electrode(s). Such electrodes are known to be poor choice for efficient reduction of iodide. To reduce the overvoltage losses, a very fine Pt-layer or islands of $\mathrm{Pt}$ are deposited on to the conducting glass electrode. This ensures high exchange current densities at the counter-electrode and thus the processes at the counter electrode do not become rate limiting in the light energy harvesting process. By developing a new mode of $\mathrm{Pt}$ deposition, we have engineered an extremely active electrocatalyst attaining exchange current densities of $>0.1 \mathrm{~A} / \mathrm{cm}^{2}$ at very low Pt-loading. This electrocatalyst is very stable and does not show long-term anodic corrosion as was observed in the case of $\mathrm{Pt}$ deposits produced by conventional sputtering or galvanic methods.

\section{Long term performance, ecological and cost factors}

Long term performance of the solar cell depends on several factors. In our earlier studies we employed colloidal preparations that contained significant amount of rutile, the UV-sensitive form of $\mathrm{TiO}_{2}$. Rutile can absorb $\approx 5 \%$ of the solar irradiation in the near UV region and such band-gap excitation leads to production of electrons and holes. The holes of $\mathrm{TiO}_{2}$ being very strong oxidant $(E>2 \mathrm{eV})$ can oxidize the organics, including the photosensitizer. Hence we need to employ a polycarbonate filter to cut off the near-UV component of the solar irradiation. Recently we have perfected the synthetic sol-gel procedures that allow preparation of colloids that contain purely anatase particles. Anatase is the high energy bandgap form of $\mathrm{TiO}_{2}\left(E_{b g}=3.2 \mathrm{eV}\right)$ and solar cells made out of anatase do not suffer from UV-sensitivity.

Concerning the dye, it undergoes two critical phases. The first is electronically excited state. Fortunately the charge injection process is extremely rapid, taking place in less than a few picoseconds ${ }^{69-75}$. Thus charge injection is a very fast channel effectively competing with other processes taking place such as population of $d-d$ states leading to photoinduced ligand loss. The second stage of concern is one after the charge injection where the sensitizer has lost one charge. Losing a charge can mean instability for many organic dyes. With inorganic complexes, charge variations often occur at the metal center and this ion is quickly retumed to the original (reduced) state by electron donation from the mediator. The Ru-complex [Ru(dcbpy $\left.)_{2}(\mathrm{NCS})_{2}\right]$ sustained more than 50 million redox cycles without noticeable loss of performance upon long time illumination, corresponding to $\approx 10$ years of continuous operation in natural sunlight. The highly porous yet compact structure of the film allows good spreading of $1 \mathrm{~m}^{2}$ surface area by using a dye solution of 1 millimolar, corresponding to an investment of $\approx U S \$ 0.07 / \mathrm{m}^{2}$ for the noble metal. 
One ton of Ru alone incorporated in the Ru-complex could provide 1 gigawatt of electric power under full sunlight. This is more than twice the total photovoltaic capacity presently installed worldwide. Thus the cost of the dye component in the solar cell will not be excessive. The most expensive part is the conducting glass electrode (s).

The present performance of $\approx 10 \%$ efficiency is well below the maximal theoretical value of $33 \%$ for conversion of AM 1.5 solar radiation to electricity by a single junction cell. One major source for the difference is the mismatch in the redox level of the dye and that of the I-/13- redox system currently used, leading to a voltage loss of $0.7 \mathrm{~V}$. Adjusting the redox levels to a more reasonable figure of $0.3 \mathrm{~V}$ would allow a significant increase in the overall efficiency. An improvement of the cell current by $\approx 30 \%$ range should also be possible through better light harvesting in the $700-900 \mathrm{~nm}$ region. An advantage of the nanocrystalline solar cell with respect to solid state devices is that its performance is remarkably insensitive to temperature change. Thus raising the temperature from $20^{\circ}$ to $60^{\circ} \mathrm{C}$ has practically no effect on the power conversion efficiency. In contrast, conventional silicon solar cells exhibit a significant decline over the same temperature range amounting to $\approx 20$ percent. Since the temperature of a terrestrial solar cell can reach readily $60^{\circ} \mathrm{C}$ under full sunlight, this feature of the present cell is particularly attractive for power generation under natural conditions.

\section{Applications of nanocrystalline $\mathrm{TiO}_{2}$ films}

Mention was made earlier on some of the possible applications one can envisage on nanocrystalline films. In Lausanne we have been pursuing some of these avenues as well. Principles of some of these applications and results in some of these are outlined below ${ }^{15}$.

\section{Nanocrystalline intercalation batteries}

In the so-called "rocking chair" batteries, electric power generation is associated with migration of $\mathrm{Li}+-$ ions from one host, i.e. $\mathrm{TiO}_{2}$ constituting anode to another host electrode, i.e. $\mathrm{NiO}_{2} / \mathrm{CoO}_{2}$ or $\mathrm{MnO}_{2}$ (cathode). The materials are used in the form of micron-sized particles, compressed pellets mixed with carbon and a polymeric binder. The morphology of the electrodes are such that large pores/channels present therein allow reversible insertion of $\mathrm{Li}$ and extraction into and from the lattice. Figure 10 shows a possible version of these batteries employing nanocrystalline films of $\mathrm{TiO}_{2}$. Studies ${ }^{76,77}$ have shown that efficient, reversible and rapid intercalation of lithium occurs due to very short diffusion time for lithium ions in these mesoscopic oxide structures. A standard size $R 921$ coin cell has been developed supplying 4 to $4.5 \mathrm{mAH}$ corresponding to $50 \mathrm{mAh} / \mathrm{g}$ capacity which compares well with the rocking chair battery having a carbon anode. These findings provide a very promising basis for the development of a new type of rechargeable battery.

\section{Electrochromic and photochromic displays}

Electrons are majority carriers on $n$-type semiconducting oxides and hence injection of electrons from outside into the junction drives the nanocrystalline oxide film into the accumulation region. Accumulation of conduction band electrons in the oxide leads to electrochromic effect, viz. development of a broad absorption in the visible and near-IR region $^{78-81}$. Electrochromic switching of mesoscopic films occurs rapidly due to ready compensation of the injected space charge by ion movement in the electrolyte present in the pores. 


\section{Nanocrystalline Li-ion battery}

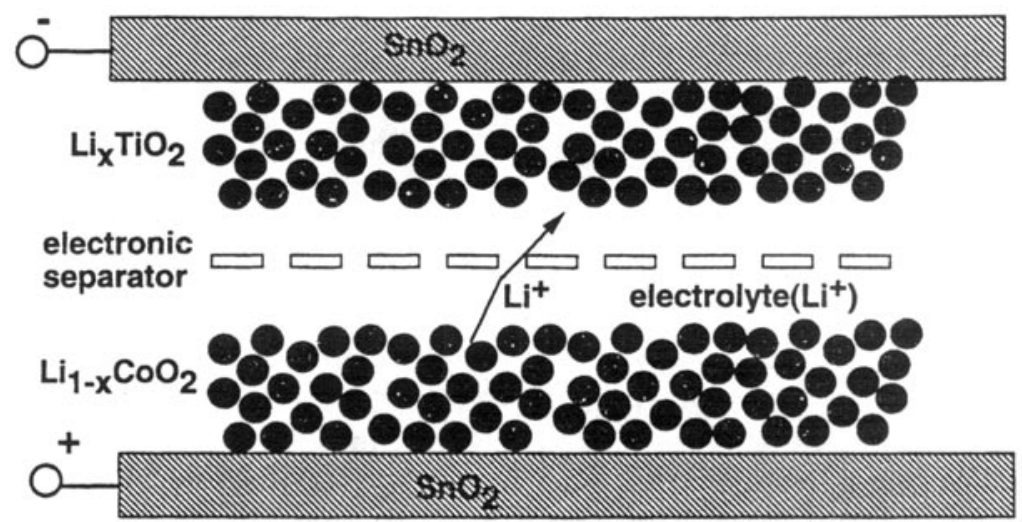

Figure 10. Lithium ion intercalation battery based on nanocrystalline $\mathrm{TiO}_{2}$ films.

\section{Electrochromic switching on surface-derivatized mesoscopic $\mathrm{TiO}_{2}$ films}
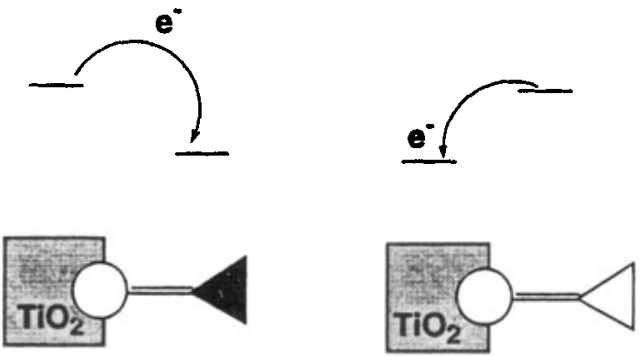

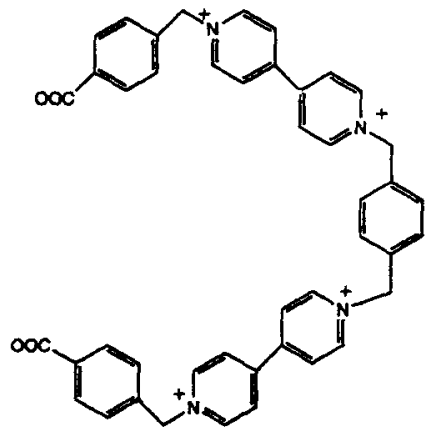

Dimeric viologen with the anchoring group

Figure 11. Electrochromic switching of surface derivatized agents on nanocrystalline oxide films.

Viologens form a group of redox indicators which undergo drastic color changes upon oxidation/reduction. The reduced form of methyl viologen for example, is deep blue while the oxidized form is colorless. Efficient reduction of anchored viologen compounds by conduction band electrons of $\mathrm{TiO}_{2}$ can be used for the amplification of the optical signal, as shown schematically in figure 11 . The amplification is due to 
orders of magnitude that are higher than the molecular extinction coefficients of these relays. Upon electroreduction, transparent nanocrystalline film of $\mathrm{TiO}_{2}$ containing viologen develop strong color and the film can be decolorised by reversing the potential. Varying the chemical structure and redox potentials of the viologens, it is possible to tune the color and hence build a series of electrochromic display devices. Such surface derivatized nanocrystalline devices accomplish a performance which in terms of figure of merit, i.e. the number of charges required to achieve an optical density change of one is already competitive with conventional electrochromic systems and hence show great promise for practical applications.

\section{Acknowledgements}

We would like to acknowledge the financial support for our work by the following Swiss agencies: Swiss National Science Foundations (FNRS), COST program of the Federal Office for Education and Science (OFES), Federal Office for Energy (OFEN) and the Commission for Technology and Innovation (CTI) and also the National Institute for Applied Photovoltaic Research (INAP), Gelsenkirschen, Germany. Progress in this truly interdisciplinary area of research has been possible only through the enthusiastic collaboration of a large number of researchers of our group over the last decade (a number of them are cited in the references given below) and we would like to acknowledge their support.

\section{References}

1 Calzaferri G 1995 Proceedings of the 10th International Conference on Photochemical Conversion and Storage of Solar Energy (IPS-10) of Interlaken, Solar Energy Mater. Solar Cells, vol. 38 and Proceedings of earlier conferences of this series cited therein.

2 Grätzel M (ed.) 1983 Energy Resources Through Photochemistry and Catalysis, Academic Press, New York

3 Schiavello M 1984 Photoelectrochemistry, Photocatalysis and Photoreactors, NATO Adv. Study Inst. Series C, vol. 146, Reidel, Dordrecht, The Netherlands

4 Serpone N and Pelizetti E 1989 Photocatalysis: Fundamentals and Applications, J. Wiley, New York

5 a) Bard A J, Fox M A 1995 Acc. Chem. Res. 28, 141; b) Lewis NS 1990 Acc. Chem. Res., 23 176; c) Kalyanasundaram K 1985 Solar Cells, 1593

6 Brinker C J and Scherer C W 1990 Sol-Gel Science: The Physics and Chemistry of Sol-Gel Processing, Academic Press, San Diego

7 Klein L C 1994 Sol-Gel Optics-Processing and Applications, Kluwer, Boston

8 Klein L C (ed.) 1988 Sol-Gel Technology for Thin Films, Fibres, Preforms, Electronics and Speciality Shapes, Noyes, New Jersey

9 a) Matijevic E 1989 Mater. Res. Soc. Bull., 4 18; b) Matijevic E 1990 Mater. Res. Soc. Bull. 5 16;

c) Mehrotra R 1992 Struc. Bonding 771

10 a) Gesser H D and Goswami P C 1989 Chem. Rev., 89 765; b) Matijevic E 1994 Langmuir, 10 8; 1986 ibid. 212

11 Matijevic E 1993 Chem. Mater. 5 412; 1985 Ann. Rev. Mater. Sci., 15485

12 Kamat P V and Meisel D (eds) 1997 Semiconductor Nanoclusters-Physical, Chemical and Catalytic Aspects, Studies in Surface Science and Catalysis series vol. 103, Elsevier, Amsterdam

13 Fendler J H 1994 Membrane Mimetic Approach to Advanced Materials, Adv. Polym. Sci, 113, Springer-Verlag, Berlin

14 Pelizzetti E 1996 Fine Particles Science and Technology: From Micro to Nanoparticles, Kluwer, Dordrecht

15 Gerfin T, Grätzel T M and Walder L 1996 Progr. Inorg. Chem., 44346 
16 Hagfeldt A and Grätzel M 1995 Chem. Rev., 9545

17 Pechy P, Rotzinger F P, Nazeeruddin Md. K, Köhle O, Zakeeruddin S M, Humphry-Baker $R$ and Grätzel M 1995 J. Chem. Soc., Chem. Commun., 65

18 Nazeeruddin Md. K, Kay A, Rodicio I, Humphry-Baker R, Müller E, Liska P, Vlachopoulos N and Grätzel M $1993 \mathrm{~J}$. Am. Chem. Soc., 1156382

19 O'Regan B and Grätzel M 1991 Nature (London) 335737

20 Nazeeruddin Md. K, Liska P, Moser J, Vlachopoulos N and Grätzel M 1990 Helv. Chim. Acta 731788

21 Vlachopoulos N, Liska P, Augustynski J and Grätzel M 1988 J. Am. Chem. Soc., 1101216

22 Liska P, Vlachopoulos N, Nazeeruddin Md. K, Comte P and Grätzel M $1988 \mathrm{~J}$. Am. Chem. Soc., 1103686

23 DeSilvestro J, Grätzel M, Kavan L, Moser J and Augustynski J 1985 J. Am. Chem. Soc., 107 2988

24 Amadelli R, Argazzi R, Bignozzi C A and Scandola F, 1990 J. Am. Chem. Soc., 1127099

25 a) Heimer T A, Bignozzi C A and Meyer G J 1993 J. Phys. Chem., 97 11987; b) Argazzi R, Bignozzi C A, Heimer T A, Castellano F N and Meyer G J 1994 Inorg. Chem., 33 5741; c) Bignozzi C A, Argazzi R, Schoonover J R, Meyer G J and Scandola F 1995 Solar Energy Mater. Sol. Cells., 38187

26 Murakoshi K, Kano G, Wada Y, Yanagida S, Miyazaki H, Matsumoto M and Murasawa S 1995 J. Electroanal. Chem., 39627

27 a) Hagfeldt A, Lindquist S and Grätzel M 1993 Sol. Energy Mater. Sol. Cells., 32 245; b) Hagfeldt A, Didriksson B, Palmquist T, Lindström H, Sodergren S, Rensmo $H$ and Lindquist S-E 1994 Solar Energy Mater. Sol. Cells. 31481

28 Knödler R, Sopka J, Harbach F and Grünling H W 1993 Sol. Energy Mater. Sol. Cells, 30277

29 a) Smestad G, Bignozzi C A and Argazzi R 1994 Sol. Energy Mater. Sol. Cells. 32 259; Smestad G, 1994 ibid 32273

30 James T H (ed.) 1977 Theory of Photographic Processes 4th edn, MacMillan Press, New York

31 Weigl J W 1977 Angew. Chem. Internat. Edn., 16374

32 Willig F and Gerischer H 1976 Top. Curr. Chem., 6131

33 Memming R in 1992 Photochemistry and Photophysics", (ed.) J F Rabek CRC Press, Boca Raton, Florida

34 Parkinson B A and Spitler M T 1992 Electrochim. Acta, 37943

35 Fujishima A and Honda K 1972 Nature (London) 23837

36 Kalyanasundaram K 1992 Photochemistry of Polypyridine and Porphyrin Complexes, Academic Press, New York

37 a) Roundhill M 1994 "Photophysics and Photochemistry of Coordination Compounds", VCH Publishers, New York; b) Sykora J and Sima J 1990 "Photochemistry of Coordination Compounds", Elsevier, Amsterdam

38 Juris A, Balzani V, Barigeletti F, Campagna S, Belzer P and Zelewski A V 1988 Coord. Chem. Rev., 8585

39 Photosensitization and Photocatalysis Using Inorganic and Organometallic Compounds, Kalyanasundaram K and Grätzel $M$ (eds), Catalysis by Metal Complexes Series, Kluwer Academic, Dordrecht, The Netherlands, 1993

40 Balzani V and Scandola F 1991 Supramolecular Photochemistry, Harwood, Chicester, UK

41 Balzani V, Juris A, Venturi M, Campagna S and Serroni S 1996 Chem. Rev., 96759 and refs. cited therein.

42 Barbé C J, Arendse F, Comte P, Jirousek M, Lenzmann F, Shklover V and Grätzel, $1996 \mathrm{~J}$. Am. Ceramic Soc., submitted

43 Kay A 1994 "Solar Cells based on Dye-sensitized Nanocrystalline $\mathrm{TiO}_{2}$ electrodes", $\mathrm{Ph} . \mathrm{D}$ dissertation, Ecole Polytechnique Federale de Lausanne, \# 1214

44 Xu Q and Anderson M A 1977 J. Am. Ceram. Soc., 771939

45 Kavan L, Grätzel M, Rathousky J and Zukal A 1996 J. Electrochem. Soc., 143394

46 Kavan L, Grätzel M, Gilbert S E, Klemenz G G and Scheel H J 1996 J. Amer. Chem. Soc., 118 6716

47 Kavan L and Grätzel M 1995 Electrochim. Acta, 40643

48 Kavan L, Kratochvilova K and Grätzel M 1995 J. Electroanal. Chem., 39493

49 Kavan L, Kay A, O'Regan B and Grätzel M 1993 J. Electroanal. Chem. 346291 
50 Kavan L, Stoto T, Grätzel M, Fitzmaurice D and Shklover V 1993 J. Phys. Chem., 979493

51 O'Regan B, Moser J, Anderson M A and Grätzel M 1990 J. Phys. Chem., 948720

52 Moser J and Grätzel M 1983 J. Am. Chem. Soc. 1056542

53 Fox M A and Channon M (eds.) 1988 'Photoinduced Electron Transfer', Elsevier, Amsterdam

54 Zakeeruddin S M, Nazeeruddin Md. K, Pechy P, Rotzinger F P, Humphry-Baker R, Kalyanasundaram K, Grätzel M, Shklover V and Haibach T 1997 Inorg. Chem., submitted

55 Grätzel M and Kalyanasundaram K 1993 in "Photosensitization and Photocatalysis using Inorganic and Organometallic Compounds", (eds) K Kalyanasundaram, M Grätzel Kluwer Academic, Dordrecht, Netherlands, p. 247-271

56 Moser J, Punchihewa S, Infelta P P and Grätzel M 1991 Langmuir, 73012

57 Houlding V and Grätzel M 1983 J. Am. Chem. Soc., 1055695

58 Vrachnou E, Vlachopoulos N and Grätzel M 1987 J. Chem. Soc., Chem. Commun., 868

59 Frei H, Fitzmaurice D and Grätzel M 1990 Langmuir, 6198

60 O'Regan B B and Schwarz D T 1995 Chem. Mater. 71349

61 Tennakone K, Kumara G R R A, Kumarasinghe A R, Wijayantha K G U and Sirimane P 1995 Semicond. Sci. Tech., 101689

62 Kalyanasundaram K and Nazeeruddin Md. K 1992 Chem. Phys. Lett. 193292

63 a) Nazeeruddin Md. K and Kalyanasundaram K 1990 Inorg. Chem., 29 1888; b) Kalyanasundaram K, Grätzel M and Nazeeruddin Md. K 1992 J. Phys. Chem., 965865 ; c) Kalyanasundaram K and Nazeeruddin Md. K 1990 J. Chem. Soc., Dalton Trans, 1657

64 a) Matsui K, Nazeeruddin Md. K, Humphry-Baker R, Grätzel M and Kalyanasundaram K 1992 J. Phys. Chem., 96 10587; b) Matsui K, Nazeeruddin Md. K, Humphry-Baker R, Vlachopoulos N, Grätzel M, Hester R E and Kalyanasundaram $K$ submitted

65 Müller E, Nazeeruddin Md. K, Grätzel M and Kalyanasundaram K 1996 New J. Chem. 30 759

66 a) Scandola F, Indelli M T, Chiorboli C C and Bignozzi C A 1991 Top. Curr. Chem., 158, 73; b) Bignozzi C A, Scandola F 1993 in "Photosensitization and Photocatalysis Using Inorganic and Organometallic Compounds", (eds) K Kalyanasundaram, M Grätzel, Kluwer Academic, Dordrecht, Netherlands

67 Wiederkehr A 1990 Biological redox reactivity of monomeric and aggregated form of molecules in solution and at interfaces, Doctoral dissertation, EPF-Lausanne Nr. 872

68 Tributsch H and Willig F 1995 Solar Energy Mater. Sol. Cells, 38355

69 Moser J and Grätzel M 1993 Chem. Phys. 176493

70 Eichberger R and Willig F 1990 Chem. Phys. 141 159; Willig F 1990 J. Am. Chem. Soc., 112 2702

71 Lanzafame J M, Palese S, Wang D, Miller R J D and Muenter A 1994 J. Phys. Chem. 9811020

72 Liu D, Kamat P V 1993 J. Phys. Chem., 9710769

73 Rehm J M, McLendon G, Nagasawa Y, Yoshihara K, Moser J and Grätzel M 1996 J. Phys. Chem., 1009577

74 Moser J, Grätzel M, Durrant J R and Klug D R 1996 in 'Femtochemistry, Ultrafast Chemical and Physical Processes in Molecular Systems',(ed.) M Chergui, World Scientific, Singapore, p. 495

75 Yan S G and Hupp J T 1996 J. Phys. Chem. 1006867

76 Huang S-Y, Kavan L, Exnar I and Grätzel M 1995 J. Electrochem. Soc., 142 L142

77 Huang S-Y, Kavan L, Kay A, Grätzel M and Exnar I 1995 Active and Passive Elec. Comp., 19 23

78 Redmond G and Fitzmaurice D 1993 J. Phys. Chem., 9711081

79 Hagfeldt A, Vlachopoulos N and Grätzel M 1994 J. Electrochem. Soc., 142 L82

80 Bonhôte P, Moser J E, Vlachopoulos N, Walder L, Zakeeruddin S M, Humphry-Baker R, Pechy P and Grätzel M 1996 J. Chem. Soc., Chem. Commun. 1163

81 Bonhôte P, Vlachopoulos N, Tingry S, Comte P and Grätzel M 1997 J. Amer. Chem. Soc., submitted 